\title{
CONSTRUÇÃO GRUPAL DO CONHECIMENTO POR UMA ABORDAGEM DIALÉTICA NA WEB
}

\author{
A DIALECTIC APPROACH TO \\ GROUP KNOWLEDGE BUILDING VIA WEB \\ LA CONSTRUCTION EN GROUPE DU SAVOIR \\ PAR UNE APPROCHE DIALECTIQUE \\ CONSTRUCCIÓN GRUPAL DEL CONOCIMIENTO \\ POR UN ABORDAJE DIALÉCTICO
}

Deller James Ferreira *

RESUMO

O presente trabalho discute a produção colaborativa do conhecimento na Web, provendo uma análise de como contribuiçôes divergentes provenientes dos individuos tornam-se um conhecimento convergente compartilhado. Uma colaboração proficua pode desencadear a criação de algo inovador que não pode ser atribuido a nenhum aluno especifico. Durante a produção colaborativa pode emergir um conhecimento que não pode ser construído individualmente. Será usada uma abordagem com base na lógica dialética, para descrever uma das possiveis maneiras pelas quais a construção do conhecimento colaborativa pode ocorrer.

Palavras-chave: Aprendizagem colaborativa. Lógica dialética. Representação social. Produção do conhecimento. Tecnologia na educação.

\footnotetext{
* Mestre em Sistemas e Computação pelo Instituto Militar de Engenharia (IME, 1990). Professora Assistente IV do Instituto de Informática da Universidade Federal de Goiás (deller@inf.ufg.br).
} 


\section{INTRODUÇÃO}

Neste artigo são utilizados os conceitos de representação social de Moscovici (2000) e da dialética de Hegel (1974) para abordar o conhecimento grupal que emerge durante a aprendizagem colaborativa na Web. O conhecimento grupal é observado considerando-se situações de resolução de problemas em um domínio pouco estruturado. Situações que permitem que sejam formuladas diversas hipóteses, por onde diferentes soluções possam ser delineadas e divergentes opiniōes possam emergir. O conhecimento grupal é considerado como o conhecimento interativamente obtido pelo discurso e que não pode ser atribuído como sendo originário de um indivíduo em particular pertencente ao grupo.

Stahl (2005) postula que o paradigma de pesquisa designado como aprendizagem colaborativa na Web é construído sobre as tradições de pesquisa de disciplinas como antropologia, sociologia, lingüística, ciência da comunicação, que são devotadas ao entendimento da linguagem, cultura e aspectos sociológicos. Contudo, não podemos omitir a grande influência da aprendizagem e desenvolvimento educacional representada por Vigotski e Piaget.

Existem múltiplas perspectivas de como o conhecimento é criado na abordagem colaborativa. Duas vertentes proeminentes são o conflito sócio-cognitivo e a abordagem histórico-cultural. O conflito sócio-cognitivo provém de Piaget (1967), e, segundo esse modelo, crianças, freqüentemente, discordam ao resolverem problemas conjuntamente. Tal confronto de diferenças em habilidades e pontos de vista é considerado desequilibrante, forçando os pares a entrarem em um conflito cognitivo, que leva ao esforço individual de re-estruturar mentalmente seu entendimento. $\mathrm{Na}$ outra visão, a construção de um novo conhecimento colaborativo se baseia na teoria histórico-cultural de Vygotsky (1978). $\mathrm{Na}$ teoria de desenvolvimento histórico-cultural, o produto cognitivo da mente individual é criado socialmente, retendo um caráter essencialmente social.

O foco deste artigo é a investigação de uma das alternativas para o processo de construção grupal do conhecimento presencial ou na Web. É analisado o processo de aprendizagem colaborativa em que membros de um grupo passam de perspectivas divergentes para a construção colaborativa do conhecimento. Tal análise vai ao encontro da perspectiva piagetiana, pois é ressaltado o papel do conflito cognitivo na criação do conhecimento.

$\mathrm{Na}$ área de aprendizagem colaborativa, existem diferentes abordagens de como alunos podem adotar estratégias para resolver as diferenças em prol da construção de um conhecimento partilhado, como, por exemplo, a construção de um senso comum (CLARK; BRENNAN, 1991) ou participação de uma comunidade de aprendizagem (LAVE; WENGER, 1991).

O termo 'aprendizagem' na aprendizagem colaborativa, usualmente, se refere a processos cognitivos relacionados ao entendimento e à aquisição do conhecimento do indivíduo. Contudo, existem trabalhos em que o aspecto colaborativo amplia o conceito de aprendizagem para a interação grupal. Stahl (2005) considera a existência de um conhecimento grupal, que é interativamente obtido pelo grupo e pode persistir em artefatos físicos ou simbólicos.

A proposta do presente trabalho é apresentar uma explicação, baseada na lógica dialética, para o processo de construção do conhecimento colaborativo que emerge do 
conflito, tendo como ponto de partida a hipótese central de que o conhecimento grupal é viável.

Como definido anteriormente, o conhecimento grupal é vislumbrado como uma das alternativas possíveis para a criação de um conhecimento compartilhado durante a prática da aprendizagem colaborativa. A existência do conhecimento grupal ressalta o lado social da criatividade. $\mathrm{O}$ produto criativo surge do grupo e não do indivíduo sendo estimulado por interações sociais.

Para Strijbos, Martens e Jochems (2004), a colaboração é um processo de diálogo, relativamente desestruturado, interativo e, acima de tudo, ativo, durante o qual participantes trabalham juntos para obter uma meta, alcançar uma decisão ou uma solução. A aprendizagem colaborativa é um processo de construção do conhecimento durante o qual estudantes ativamente buscam a informação, engajam-se em discussões críticas, formulam questôes, discutem respostas, fazem propostas e replicam outras propostas (VEERMAN; VELDHUIS-DIERMANSE, 2001). A aprendizagem colaborativa é adequada para tarefas nas quais estudantes são engajados em uma produção conjunta. Alunos ativam processos mentais superiores, tal qual a síntese do conhecimento. Koschmann (2002) caracteriza a área de aprendizagem colaborativa na Web como o estudo de práticas de construção de sentidos em um contexto de atividade conjunta e das formas nas quais essas práticas são mediadas por meio de artefatos projetados. Torres et al. (2004) postulam que a aprendizagem colaborativa é uma estratégia que encoraja a participação do estudante no processo de aprendizagem e que faz da aprendizagem um processo ativo e efetivo.

O conhecimento não seria o que é se não fosse social, e os processos de apropriação do conhecimento não seriam o que são se a interação inter-individual não desempenhasse um papel essencial. Mas é preciso salientar que isso não significa em absoluto que o sujeito possa ser minimizado (VERNAUD, 1989). Portanto, é importante estudar em detalhe a inter-relação entre o sujeito individual e o grupo e quais influências mútuas ocorrem. $\mathrm{O}$ indivíduo não pode ser esquecido, nem tampouco sub-valorizado na aprendizagem colaborativa, mesmo quando o conhecimento grupal é reconhecido. Alunos influenciam-se mutuamente durante o processo de aprendizagem, por meio de processos comunicativos, o que enfatiza a dialética do individual e do social.

Pesquisas em tecnologia da educação exploram inter-relações entre interesses individuais e grupais. Pillay e Elliot (2003) argumentam que, atualmente, são cobradas habilidades como liderança, responsabilidade e desenvolvimento individual. Por outro lado, emergem ambientes de trabalho que priorizam a comunidade, onde o trabalho ocorre em conjunto. É esperado que um indivíduo contribua para o coletivo e, ao mesmo tempo, tenha responsabilidade pelos seus atos. Segundo Pea (1993), quando a aprendizagem individual é facilitada por processos inter-pessoais ou se o conhecimento surge entre os participantes, grande parte da aprendizagem ocorre como resultado de uma ajuda recíproca. Para ilustrar essa idéia, Breslow (2004) será citado, tomando seu exemplo de alunos de matemática que, na maioria dos casos, precisam pensar em um problema antes que possam discutir com outra pessoa. Aprender matemática requer capacidades cognitivas que estão diretamente relacionadas à aprendizagem individual, 
enquanto que problemas de projeto adequam-se melhor a atividades em grupo, sendo o produto o resultado de esforços intelectuais em um mesmo sentido.

Esse tema foi abordado por alguns pesquisadores como Perkins (1993), sugerindo que discussões sobre o pensamento crítico devem incluir dimensões sociais, disposicionais e psicológicas. Eles advogam que resolução de problemas, tomada de decisões, pensamento racional e auto-reflexão, bem como outros conceitos de aprendizagem são amplamente abordados pela psicologia cognitiva, exclusivamente, por um ponto de vista do indivíduo. Existe uma necessidade de expandir o escopo do pensamento crítico, pois ser crítico envolve o questionamento de normas e valores socioculturais, práticas sociais e pressupostos sobre ferramentas, processos, padrōes e circunstâncias presentes no ato de aprendizagem. Encontrar um balanço entre realizar uma tarefa individualmente ou em grupo, tendo em mente que a aprendizagem de um aluno afeta outros alunos e o grupo como um todo, é um fator essencial.

Koschman et al. (2005) argumentam acerca da necessidade do estudo sobre os métodos de construção conjunta do conhecimento durante a aprendizagem colaborativa. Suthers (2005) aponta que é necessário um entendimento de como os eventos de aprendizagem se dão ao curso das interações. Pouca atenção tem sido remetida à produção grupal de conceitos na área de aprendizagem colaborativa. Poucos estudos abordam diretamente o tema, como, por exemplo, Koschman et al. (2005), Koschman et al. (2003), Stahl (2005), Stahl (2004) e Stahl (2003).

O tema 'construção grupal do conhecimento' dá margem a muitas questôes em aberto interessantes, tais quais: em quais as condições em aprendizagem colaborativa é mais profícua que a aprendizagem individual? $\mathrm{O}$ fenômeno cognitivo transcende o indivíduo? É possível que a aprendizagem usualmente concebida como uma função cognitiva seja distribuída ao longo de pessoas e artefatos? A questão central de pesquisa abordada no presente artigo é relativa à existência do conhecimento grupal. A hipótese central a ser discutida é como ocorre uma manifestação possível do conhecimento grupal. É apresentada como uma alternativa um processo de elaboração de uma representação social por meio de uma síntese dialética.

O tipo de problema apresentado aos alunos exerce influência direta sobre a quantidade e o tipo das interaçôes na busca de uma solução conjunta. Problemas menos estruturados e pouco definidos propiciam o surgimento de opiniōes divergentes, permitindo que os alunos explorem uma variedade de perspectivas (PUTAMBEKAR, 2005). Considerando-se o tipo de impacto diferenciado na produção do conhecimento em função da situação educacional, a análise dialética apresentada será demarcada, neste trabalho, por um contexto de aprendizagem em um domínio de solução de problemas complexo e pouco estruturado, englobando casos situados no mundo real e onde é considerado, além da aprendizagem colaborativa, o estudo individual como uma forma de promover o pensamento divergente. Deste modo, o aprendiz tem a oportunidade de gerar múltiplas hipóteses e explorar mais informação com o intuito de refinar tais hipóteses e caminhar na direção de uma solução em uma situação educacional de aplicação prática de conhecimentos teóricos. 


\section{CONSTRUÇÃO DO CONHECIMENTO COMO A CRIAÇÃO DE UMA REPRESENTAÇÃO SOCIAL}

Neste artigo é advogado que a aprendizagem colaborativa na Web envolve um balanço entre processos grupais e individuais. Um grupo de alunos pode, em ocasião e condições favoráveis, construir conhecimento que excede o conhecimento individual dos membros do grupo. Esse conhecimento grupal pode estar explicitado em representaçôes computacionais ou materializar-se como uma representação social.

A análise de Stahl (2003) demonstra uma noção da natureza do conhecimento grupal. Segundo o autor, o conhecimento grupal não pode ser considerado como um tipo de média entre os componentes do grupo. O conhecimento grupal não é um acordo sobre conhecimentos prévios, nem tampouco uma sobreposição de conhecimentos individuais.

O conhecimento grupal é construído por meio das interações dos membros individuais do grupo, não pelos indivíduos sozinhos. É uma propriedade emergente do discurso e interação, a qual não é, necessariamente, reduzível às opiniōes e entendimento dos indivíduos. A diversidade de perspectivas pode levar a um conhecimento mais elaborado. O conhecimento grupal representado é posteriormente compartilhado pelos indivíduos do grupo. O conhecimento que estamos abordando neste ensaio, inicialmente, possui uma característica divergente e é sintetizado no processo de interação, dando origem a um conhecimento convergente, o qual é, após sua representação em artefatos, internalizado pelos componentes do grupo. Os membros do grupo constroem sua própria interpretação do conhecimento grupal.

Para Stahl (2005), o conhecimento grupal envolve uma questão de cognição grupal, que deve ser vista de uma forma metodológica, e não ontológica. É defendida uma posição a favor da existência de um significado partilhado pelo grupo. O grupo "aprende" à medida que o indivíduo aprende, e o indivíduo aprende conforme o grupo "aprende".

A maior dificuldade em entender o conhecimento compartilhado é a visão usual de associar pensamentos e intenções a indivíduos e reduzir o fenômeno do grupo a açôes dos indivíduos do grupo. O conhecimento grupal é interativamente obtido pelo diálogo e não pode ser atribuído a um indivíduo específico. A análise da aprendizagem deve ser feita considerando-se o indivíduo como unidade de análise, bem como o grupo como unidade de análise e, também, deve-se levar em consideração as trocas que ocorrem entre tais entidades.

A discussão corrente na aprendizagem colaborativa acerca da elaboração do conhecimento compartilhado critica a proposta tradicional de Clark e Brennan (1991). A elaboração do conhecimento compartilhado, de acordo com Clark e Brennan, enfoca sua negociação a curto prazo durante interações breves de forma seqüencial. O processo descrito por tais autores nem sempre é útil para explicar a geração conhecimento grupal. No presente trabalho, o processo de construção do conhecimento grupal será vislumbrado como a criação de uma representação social. Nesse caso, a representação social é a unidade de análise aqui proposta, sendo que a representação social abarca os planos individual e social, bem como suas inter-relações. 
Moscovici (2000) define uma representação social como um sistema de valores, idéias e práticas, com uma dupla função: primeiro, estabelecer uma ordem que possibilita às pessoas orientar-se em seu mundo material e social e controlá-lo; e, em segundo lugar, permitir que a comunicação seja possível entre os membros de uma comunidade, fornecendo-lhes um código para nomear e classificar, sem ambigüidade, os vários aspectos de seu mundo e da sua história individual e social.

Para Jodelet (1984), o conceito de representação social designa uma forma específica de conhecimento, o saber do senso comum, cujos conteúdos manifestam a operação de processos generativos e funcionais socialmente marcados. Mais amplamente, designa uma forma de pensamento social. A marcação social dos conteúdos ou dos processos de representação refere-se às condiçóes e aos contextos nos quais emergem as representações, às comunicações pelas quais elas circulam, às funçôes que elas servem nas interaçôes com o mundo e com os outros. Jodelet (1984) proporciona a seguinte definição sintética sobre o termo representação social: representações sociais são uma forma de conhecimento, socialmente elaborada e partilhada, tendo uma visão prática e concorrendo para a construção de uma realidade comum a um conjunto social.

O conhecimento produzido durante a aprendizagem colaborativa na Web, dentro de uma situação educacional complexa, pouco estruturada e situada no mundo real pode ser considerada como um caso particular de representação social, como definido anteriormente por Jodelet (1984). Em outras palavras, a aprendizagem colaborativa na Web é um processo social onde a representação deve ser situada, tendo seu fenômeno de gênese observado. A aprendizagem colaborativa na Web, sendo mediada pelo computador, além de suas especificidades aprendizagem e colaboração, possui como particularidade adicional a possibilidade de transcender o aspecto conceitual das representaçóes sociais. Nesse caso, representaçóes sociais são materializadas em um artefato digital e seu aspecto dinâmico de gênese e transformação pode ser visualizado e facilitado.

Uma outra particularidade do presente trabalho é investigar as inter-relações entre os planos individual e grupal (social) durante a produção do conhecimento partilhado na aprendizagem colaborativa. São evitados reducionismos que consideram indivíduos como meros processadores de informação ou portadores de crenças coletivas. Indivíduos são pensadores ativos que, por meio de episódios de interação social, produzem representaçôes. Essa característica vai ao encontro de preocupaçōes que aparecem em estudos de representaçóes sociais. No caso das representações sociais, o fato de que se trate de uma forma de conhecimento acarreta o risco de reduzi-la a um evento intra-individual, onde o social intervém apenas secundariamente, bem como o fato de se tratar de uma forma de pensamento social acarreta o risco de diluí-la nos fenômenos culturais ou ideológicos (JODELET, 1984).

Para Moscovici (2000), a tarefa primordial da psicologia social é o estudo das representaçôes sociais, suas propriedades, suas origens e seu impacto, e, apesar de numerosos estudos posteriores e do avanço científico desde a definição da mente coletiva de Durkheim, as representaçôes sociais são um campo em evolução, tendo muito a ser explorado a respeito de processos de gênese e transformação de representaçôes sociais. 
O primeiro pesquisador a se preocupar com a gênese e influências sociais das representaçôes coletivas foi Durkheim (1982). Em sua época, o que se referia às leis do pensamento coletivo era totalmente desconhecido. De acordo com Durkheim, a conceitualização não era nada mais que criar uma palavra descrevendo todo o tipo de variadas generalizações, vagas, sem um objeto definido como foco. Para o autor, era necessário descobrir, pela comparação de mitos, lendas, tradições populares e linguagens, como as representaçóes coletivas se atraem e se excluem, como se mesclam ou se distinguem.

Durkheim analisou as noções fundamentais de ciência, como a formação de conceitos. Para o autor, se partirmos do pressuposto de que a matéria do pensamento lógico é feita de conceitos, então, investigar como a sociedade pode ter desempenhado um papel na elaboração do pensamento lógico é o mesmo que questionar qual foi a sua contribuição na formação dos conceitos.

O conceito, para Durkheim (1996), não é, simplesmente, uma generalização. $\mathrm{O}$ indivíduo possui o poder de captar o que objetos têm de comum para prover uma generalização; contudo, ele não considera plausível que o pensamento lógico seja exclusivamente caracterizado pela extensão maior das representações individuais que o constituem, não podendo ser restrito ao indivíduo. Um conceito é uma representação essencialmente impessoal, não traz a marca de nenhuma inteligência particular. A sua universalidade não pode ser confundida com a generalização, sendo a propriedade que o conceito possui de ser comunicado. Os conceitos são representaçôes coletivas, são idéias gerais que exprimem categorias e classes mais do que objetos particulares, captando propriedades gerais.

Durkheim (1996) acreditava que as representaçôes coletivas eram dotadas de uma "energia psicológica" superior àquelas individuais. Deste modo, as representaçôes coletivas sobrepujam as representações individuais. Essa energia emerge de um processo chamado de fusão. Para Durkheim, representações coletivas são o produto de imensa cooperação que se dá no espaço e tempo, na qual pessoas diversas associam e combinam suas idéias ao longo de geraçóes. A gênese descrita por Durkheim surge fortemente com base em características individuais, tais quais autonomia e exterioridade.

Se alguém nos expressa uma idéia que já nos é conhecida, a representação que temos sobre ela é adicionada a essa nova noção, sendo supra-imposta e se confundindo com ela. Dessa fusão surge uma nova idéia que absorve as precedentes (DURKHEIM, 1947).

Durkheim desencadeou uma mudança radical na sociologia, com sua definição de representações coletivas; contudo, a sua maior crítica é relacionada à associação de um caráter estático a sua preocupação entre o coletivo e o individual. Sua definição de representação coletiva é delineada pela fixação e a cristalização. O conceito situa-se fora do tempo e do devir, sendo, relativamente, imutável.

Moscovici foi buscar na sociologia de Durkheim um primeiro abrigo conceitual para sua teoria acerca de representaçôes sociais. Moscovici utiliza o termo representaçôes sociais, em vez de representações coletivas, para atribuir um caráter dinâmico às representações. Quando um grupo está passando por mudanças, ocorrem tensōes, tendo como resultado novas descobertas, concepções, e a sua conseqüente popularização na linguagem do 
dia-a-dia. Além disso, a representação social influencia o indivíduo, mas não se impõe a ele, já que indivíduos possuem muitos modos de pensar e representar, não havendo uma intersubjetividade total.

Enquanto Durkheim visualiza as representações coletivas como formas estáveis de compreensão coletiva, com o poder de integração da sociedade, Moscovici explora a variação e a diversidade das idéias coletivas nas sociedades modernas. $\mathrm{O}$ indivíduo é um ser social não passivo, inserido em uma sociedade, a qual não é um lugar destinado para reduzir as incertezas dos indivíduos, mas um sistema de relações entre indivíduos atrelados a uma coletividade.

O conceito de representações coletivas de Durkheim abrangia uma gama ampla e heterogênea de formas de conhecimento, supondo-se estar nelas concentrada uma grande parte da história intelectual da humanidade. Em Moscovici, as representações sociais são reduzidas a uma forma específica de conhecimento, tendo como função a comunicação entre indivíduos no quadro da vida cotidiana.

As representações que endereçam o trabalho de Moscovici não remetem a épocas remotas, mas são aquelas da sociedade presente nos planos científico e humano, que não são sedimentadas nem imutáveis. Em qualquer cultura há momentos de tensão em que novas representações se manifestam. No curso da elaboração de representações sociais, não é manifestado um acordo entre nossas idéias e a realidade, com o intuito de simplificar um mundo complexo, mas sim um esforço no sentido de construir um mapeamento entre o estranho e o familiar. As representaçôes sociais têm como propósito fundamental reduzir o vago, por meio de um certo grau de consenso entre as pessoas de um grupo. A interdependência da cultura e da mente do indivíduo é um aspecto importante das representações sociais, no qual a estrutura cognitiva e a cultura se constituem mutuamente. As representaçôes sociais emergem em um movimento em contexto baseado em uma realidade concreta.

O enfoque proposto por Moscovici é um avanço das idéias de Durkheim, portanto o modo pelo qual as representações sociais são criadas não foi detalhado de forma suficiente. Para Moscovici e Hewstone (1984), além do senso comum concebido como um corpo de conhecimentos produzido espontaneamente pelos membros de um grupo e fundado na tradição e no consenso, surge um novo tipo de senso comum, novos saberes sociais ou populares, conhecimentos de segunda mão, cuja operação básica consiste na contínua apropriação das imagens, das noções e das linguagens que a ciência não cessa de inventar.

Moscovici considera a síntese das representações sociais como conjuntos de conceitos, afirmações e explicações referentes à construção de realidades sociais. Na gênese das representações sociais é gerado um conhecimento a partir de uma compreensão alcançada por indivíduos que pensam, mas não sozinhos. Sabe-se que a criação de uma representação se dá nas mesmas circunstâncias e, ao mesmo tempo, que se manifesta em interaçôes sociais e pelo diálogo. Contudo, ainda há muito a ser revelado sobre a construção das teorias do senso comum, termo este utilizado por Moscovici para designar as representações sociais. Para Moscovici, uma idéia chave na gênese das representações 
sociais é a familiarização, ou seja, absorver um conceito que não se encaixa de forma precisa nas categorizações conhecidas por um indivíduo.

Os processos pelos quais são construídos conceitos de modo coletivo - como o conhecimento grupal constitui-se ao longo das interaçōes entre os elementos de um grupo não foram totalmente revelados. Jodelet (1984), em uma tentativa de demarcar o campo das representações sociais, aponta as representaçôes sociais como modalidades de pensamento prático orientadas para a comunicação, apresentando características específicas no plano da organização dos conteúdos das operações mentais e da lógica. Portanto, não explora como tais operações mentais e tal lógica se manifestam. Há a necessidade de esforços de esclarecimento e elaboração conceituais a serem despendidos.

Neste trabalho, será evocada uma visão dialética para caracterizar o mecanismo do desenvolvimento do conhecimento grupal oriundo da aprendizagem colaborativa na Web, que emerge como uma representação social com base em opiniōes divergentes. Em outras palavras, as representaçôes sociais serão usadas como ponto de partida e referencial teórico para uma explanação sobre a produção do conhecimento partilhado na aprendizagem colaborativa na Web, e sua gênese será visualizada como um processo descrito pela lógica dialética.

O casamento das representaçôes sociais com a lógica dialética leva em consideração não apenas o aspecto mentalista da produção do conhecimento, originalmente proposta por Hegel, mas também o conhecimento que está no mundo. A interação entre pessoas e entre pessoas e seu ambiente social possui papel fundamental na criação do conhecimento. Aspectos especificamente relacionados com a tecnologia, como o modo pelo qual a representação pode ser externalizada e manipulada em um artefato digital, não são objetivos deste trabalho, sendo deixados para uma investigação futura.

\section{ABORDAGEM DIALÉTICA DA CONSTRUÇÃO DO CONHECIMENTO GRUPAL}

Uma das facetas mais importantes da aprendizagem colaborativa é que, a partir de uma discussão em um grupo, um aluno pode obter uma compreensão mais profunda e mais ampla do assunto que está sendo estudado, ou seja, o aluno deve construir novos entendimentos com base no diálogo. O processo pelo qual alunos obtêm um conhecimento mútuo, sobrepujando suas perspectivas individuais, pode advir de um processo de síntese.

A chave para um entendimento do processo de criação do conhecimento mútuo a partir do conhecimento divergente pode ser a lógica dialética. A lógica dialética fornece uma base teórica para o entendimento da criação do conhecimento como um processo transcendente por meio do qual indivíduos ultrapassam seus limites, adquirindo uma nova identidade. Desse modo, o indivíduo tenta invocar uma realidade mais ampla a partir da síntese de diversos ângulos.

Do dicionário Oxford, síntese pode ser definida como o processo ou resultado da construção de elementos separados, especialmente idéias, em um todo conexo, principalmente em uma teoria ou sistema. 
Essa definição é direta, mas a interpretação do processo pode variar consideravelmente. Um ponto de vista é considerar a síntese como um processo entendido partindo-se do método de raciocínio que Hegel chamou de dialética: um fenômeno (uma tese) atua contra outro (a antítese) para produzir algo totalmente novo (a síntese). A síntese pode ser vislumbrada como um ponto de vista superior, retendo o que a tese e a antítese englobam em comum.

O movimento dialético, na dialética hegeliana, é uma dinâmica na qual novas realidades são explicitadas, deduzidas por meio da contradição, ou seja, por uma oposição existente em uma realidade prévia. Uma vez apresentada a oposição, a partir de duas idéias contraditórias é evocada uma nova identidade em um terceiro momento chamado de síntese. A síntese faz suspender ou cessar a contradição entre a tese e a antítese.

$\mathrm{Na}$ lógica formal há uma abstração de conteúdo, enquanto que na lógica dialética a idéia é considerada concreta, sendo o movimento dialético tomado como o concreto em evolução. A lógica dialética está vinculada à formação de conceitos, enquanto que na lógica formal há preocupação com a relação entre conceitos. O diálogo dialético é situado em um contexto baseado no mundo real.

Uma inter-relação entre a síntese de representações sociais e conflito é apontada em passagem de Moscovici (2000, p. 174), com o propósito de responder o porquê da criação de representaçôes sociais: "A dinâmica dos relacionamentos é uma dinâmica de familiarização, onde objetos, indivíduos e eventos são percebidos e compreendidos em relação a encontros ou paradigmas prévios". Tais paradigmas trazidos de indivíduos diversos podem ser conflitantes.

O tipo de conhecimento gerado pela lógica dialética não é aquele obtido por um raciocínio analítico, no qual contradições são resolvidas pela lógica formal e não pela síntese. No princípio de construção de conhecimento que queremos demonstrar, indivíduos externalizam suas posições para que sejam compartilhadas com seus pares, tornandoos a base para o novo conhecimento. Durante tal processo de externalização, indivíduos tentam articular suas idéias pelo uso de metáforas, analogias, modelos ou outras estratégias que permitam mapeamentos de diferentes domínios.

Um diálogo dialético ocorre entre os participantes quando são levantadas questóes que se contrapõem e o conteúdo é sintetizado, criando-se um novo conhecimento, considerando-se o conteúdo vinculado a sua forma. Um conhecimento não é criado em um vácuo; é necessária uma interpretação para que a informação se transforme em conhecimento. Em nossa proposta de síntese consideraremos o trabalho de Varela e Shear (1999), no qual deve haver pelo menos três componentes no grupo e três diferentes papéis a serem desempenhados.

O processo de construção do conhecimento ocorre em três etapas. Primeiramente, o primeiro participante tem o papel de inovador, levantando uma nova realidade. Em seguida, a segunda pessoa interage com a primeira pessoa e levanta um ponto de vista pessoal e oposto. Finalmente, a terceira pessoa, de um ponto de vista superior, atrela-se a uma trans-subjetividade e cria uma nova realidade tangível e compartilhável. Um observador supostamente "objetivo" observa o debate e forma a síntese, que consiste dos 
elementos mais plausíveis da tese e da antítese. A síntese representa um entendimento em um nível mais abstrato que dissipa o conflito definitivamente.

É possível que a tese e a antítese colidam de tal modo que a tese seja totalmente abandonada. Por outro lado, a dialética de Hegel levanta outra possibilidade: aquela em que a antítese sugere que a tese possa ser reforçada pela aplicação de restriçóes adicionais. Desta forma, propomos que a terceira pessoa direcione seu raciocínio no sentido de examinar as implicações da tese e como determinadas mudanças podem afetá-las. A antítese deve ser encarada pelo terceiro indivíduo como um refinamento da tese, enquanto que o papel dos outros dois participantes é o de defender seus pontos de vista específicos em direções totalmente divergentes. Após a síntese, o novo conhecimento deve ser interpretado por todos os participantes.

Pelo processo de síntese descrito anteriormente, pode ser obtido um conhecimento que não pode ser totalmente atribuído a nenhum componente do grupo, caso a terceira pessoa parta dos resultados fornecidos pelos dois primeiros participantes sem se preocupar com seu processo de formulação, ou seja, sem ter um conhecimento total do que foi explicitado. Portanto, foi apresentado um caso em que o conhecimento grupal pode ocorrer. A terceira pessoa observa o debate e se concentra em elaborar formulações a partir dos resultados diametralmente opostos. A veracidade de cada resultado fica a cargo da primeira e da segunda pessoa. Deste modo, é criado um conhecimento, o qual não pode ser atribuído exclusivamente a um dos integrantes do debate.

\section{CONCLUSÕES}

Após a criação do conhecimento grupal, os componentes do grupo devem interpretar o produto final, entrando em um processo de representação social de familiarização, o que pode levar a novas reflexões. Deste modo, a criação do conhecimento grupal é algo dinâmico, estando sempre em evolução. Do ponto de vista educacional, a criação contínua do conhecimento em uma aplicação prática desenvolve a capacidade de reflexão dos alunos correlata ao "saber o porquê". Neste sentido, a aprendizagem não está restrita ao "saber fazer", que, usualmente, acompanha a experiência prática no âmbito educacional. A ênfase na busca por explicações que gerem um novo conhecimento permite ao aluno a reflexão acerca do conhecimento como um processo inovativo. Dito de outro modo, um mapeamento entre um domínio conceitual e um domínio de problema surge como um produto criativo.

Um aspecto fundamental na criação do conhecimento grupal é a diversidade entre os alunos. Cada aluno deve contribuir de modo significativo, reconhecendo diferentes aspectos do problema e suas possíveis soluçōes. A diversidade de pensamento é uma das condições que tornam a aprendizagem colaborativa profícua. Para que o diálogo seja efetivo, posiçôes e opiniōes relevantes e diversas devem ser externalizadas pelos alunos como base para uma reflexão conjunta.

Um elemento crucial na abordagem dialética provida é a reflexão crítica e a transitividade entre os alunos expressa na tese e na antítese, levando a uma convergência de 
opiniōes divergentes apresentadas. A partir daí, a aprendizagem individual não é descartada nem tampouco desvalorizada, sendo um pré-requisito para a aprendizagem colaborativa. Apesar da existência de um conhecimento que não pode ser atribuído a nenhum elemento do grupo, não se trata de a aprendizagem colaborativa ser mais produtiva que a aprendizagem individual, mas sim de ambas serem essenciais e complementares.

Quanto à pergunta relativa à possibilidade de o fenômeno cognitivo transcender o indivíduo, em outras palavras, afirmamos que o fenômeno da aprendizagem colaborativa não ocorre apenas no plano individual, ocorrendo também em interações com outros indivíduos e representações, destacando não só o aspecto mentalista, mas também enfocando a influência da ação, mais especificamente da interação sobre outros indivíduos e o mundo que nos cerca. Desta forma, podemos dizer que a aprendizagem colaborativa é distribuída entre pessoas e artefatos.

Elaborar artefatos digitais como representaçōes sociais, deixando evidente seu aspecto dinâmico, permitindo que alunos articulem suas idéias de modo conjunto, é meta de investigação futura. A aprendizagem colaborativa na Web é mediada pelo computador, o qual é uma ferramenta que possui o potencial de transcender suportes tradicionais para o processo de descoberta. É neste sentido que é pretendida elaboração de representaçõos digitais.

\section{Referências}

BRESLOW, Lori. Lessons learning: findings from ten formative assessments of educational initiatives at MIT. 2004.

CLARK, Herbert; BRENNAN, Susan. Grounding in communication. In: RESNICK, L. B.; LEVINE, J. M.; TEASLEY, S. D. (Eds.). Perspectives on socially shared cognition, Hyattsville, MD: American Psychological Association, 1991. p. 127-149.

DURKHEIM, Émile. The rules of sociological method. London: Macmillan, 1982.

. As formas elementares da vida religiosa. Petrópolis: Vozes, 1996.

. The division of labor in society. New York: The Free Press, 1947.

HEGEL, Georg Wilhelm Friedrich. Hegel: essencial writings. New York: Harper \& Row Publishers, 1974.

JODELET, Denise. Représentation sociale: phénomènes, concept et théorie. In: MOSCOVICI, Serge (Org.). Psychologie Sociale. Paris: PUF, 1984. p. 357-378.

KOSCHMANN, Timothy. Dewey's contribution to the foundations of CSCL research. Proc Computer Supported Collaborative Learning, Boulder, January 7-11, p. 17-22, 2002.

Proceedings of the international conference on computer support for collaborative learning ; ZEMEL, Allan; CONLEE-STEVENS, Melinda; YOUNG, Nata; ROBBS, Julie; BARNHART, Amber. How do people learn? Members' methods and communicative mediation. In: BROMME, R.; HESSE, F. W.; SPADA, H. (Eds.). Barriers and biases in computer-mediated knowledge communication (and how they may be overcome). Amsterdam: Kluwer Academic Press. 2005. p. 265-294. 
KOSCHMANN, Timothy; ZEMEL, Allan; CONLEE-STEVENS, Melinda; YOUNG, Nata; ROBBS, Julie; BARNHART, Amber. Problematizing the problem: a single case analysis of a PBL meeting. In: WASSON, B.; LUDVIGSEN, S.; HOPPE, U. (Eds.). Designing for change in networked learning environments: Proceedings of the international conference on computer support for collaborative learning (CSCL '03). Amsterdam: Kluwer Academic Press, p. 37-43. 2003.

LAVE, Jean; WENGER, Etienne. Situated learning: legitimate peripheral participation. Cambridge: Cambridge University Press, 1991.

MOSCOVICI, Serge. Social influence and social change. London: Academic Press, 1976. Social representations: explorations in social psychology, Cambridge, UK: Polity Press, 2000.

; HEWSTONE, M. De la science au sens commun. In: MOSCOVOCI, Serge (Ed.). Psychologie Sociale. Paris: Presses Universitaires de France, 1984. p. 211-250.

PEA, Roy. Practices of distributed intelligence and designs for education. In: SALOMON, G. (Ed.). Distributed Cognitions: Psychological and Educational Considerations. Cambridge: Cambridge University, 1993. p. 47-88.

PERKINS, David. Person Plus: a distributed view of thinking and learning. In: SALOMON, G. (Ed.). Distributed Gognitions: Psychological and Educational Considerations. Cambridge: Cambridge University, 1993. p. 88-110.

PIAGET, Jean. La psychologie de l'intelligence. Paris: Armand Colin, 1967.

PILLAY, Hitendra; ELLIOT, Robert. Distributed learning: Understanding the emerging workplace knowledge. Journal of Interactive Learning Research, v. 93, n. 18, p. 93-110, 2003.

PUTAMBEKAR, Sadhana. Analyzing Collaborative Interactions: Divergence, Shared Understanding and Construction of Knowledge. Computers \& Education, Article in Press. 2005.

STAHL, Gerry. Building Collaborative Knowing: Elements of a Social Theory of CSCL. In: STRIJBOS, J. W.; KIRSSCHNER, P.; MARTENS, R. (Eds.). What We Know about CSCL: And Implementing it in Higher Education. p. 53-86, Boston, MA: Kluver Academic Publishers, 2004.

Communication and Learning in Onlinet aliilaboration. Group'03, November 9-22, Sanibel Island Florida, 2003.

Group Cognition in Computer Assisted Collaborative Learning. Journal of Computer Assisted Learning, 2005.

STRIJBOS, Jan-Willem; MARTENS, Rob; JOCHEMS, Wim. Designing for Interaction: Six Steps for Designing Computer-supported Group-based Learning. Computers \& Education, v. 42, p. 403-424, 2004.

SUTHERS, David. Technology Affordances for Intersubjective Learning: A thematic Agenda for CSCL. In: KOSCHMANN, T.; D. SUTHERS, D.; CHAN, W. (Eds.). Computer Supported Collaborative Learning 2005: The Next 10 Years! Mahwah, NJ: Lawrence Erlbaum Associates; International Society of the Learning Sciences, 2005. p. 135-144.

TORRES, Patrícia; ALCÂNTARA, Paulo Roberto; IRALA, Esrom; FREITAS, Adriano. Grupos de consenso: uma proposta de aprendizagem colaborativa para o processo de ensino-Aprendizagem. Revista Diálogo Educacional, Curitiba, v. 4, n. 13, p. 129-145, set.-dez. 2004. 
VARELA, Francisco; SHEAR, Jonathan. First person methodologies: what, why, how? In: ; ____ (Eds.). The View From Within. Thoverton: Imprint Academic, 1999. p. 1-14.

VEERMAN, Arja; VELDHUIS-DIERMANSE, Else. Collaborative Learning Though Computer Mediated Communication in Academic Education. In: Euro CSCL Conference, Maastricht, Holland, 2001. p. 625-632.

VERNAUD, Grazzini. Questions vives de la psychologie du développement. Bulletin de Psychologie, Paris, v. 42, n. 390, p. 450-457, 1989.

VYGOTSKY, Liev Semionovitch. Mind in society. Harvard: Harvard University Press, 1978. 


\section{A dialectic approach to group knowledge construction}

\section{Abstract}

The present essay discusses collaborative knowledge construction on the Web, providing an analysis related to how divergent contributions from individuals become a convergent shared knowledge. A proficient collaboration can unlash the creation of something innovating that can not be conferred to a specific student. During the collaborative production a knowledge that could not be constructed individually can emerge. An approach based on dialectic logic to describe one of the possible ways that such a process concerning collaborative knowledge construction can occur by means of a social representation synthesis will be used.

Keywords: Collaborative learning. Dialectic logic. Social representation. Knowledge construction. Technology in education.

\section{La construction en groupe du savoir par une approche dialectique}

\section{Résumé}

Le travail discute la production collaborative du savoir sur la Web, fournissant une analyse qui a rapport à comment des contributions divergentes provenant des individus deviennent un savoir convergent partagé. Une collaboration enrichissante peut entraîner la création de quelque chose d'innovateur qui ne peut être conféré à aucun étudiant en particulier. Durant la production collaborative peut émerger un savoir qui ne peut être construit individuellement. Une approche sur base de la logique dialectique pour décrire une des manières possibles que tel processus concernant la construction du savoir collaboratif peut prendre place par l'entremise de la synthèse d'une représentation sociale sera utilisée.

Mots clefs : Apprentissage collaboratif. Logique dialectique. Représentation sociale. Production du Savoir. Technologie en Éducation.

\section{Construcción grupal del conocimiento por un abordaje dialéctico}

\section{Resumen}

El presente trabajo discute la producción colaborativa del conocimiento en la web, proveyendo un análisis relacionado a como contribuciones divergentes provenientes de los individuos se tornan un conocimiento convergente compartido. Una colaboración proficua puede desencadenar la creación de algo innovador que no puede ser conferido a ningín alumno especifico. Durante la producción colaborativa puede emergir un conocimiento que no puede ser construido individualmente. Será usado un abordaje con base en la lógica dialéctica para describir una de las posibles maneras que tal proceso concermente a la construcción colaborativa del conocimiento puede ocurrir por medio de la sintesis de una representación social.

Palabras-clave: Aprendizaje colaborativo. Lógica dialéctica. Representación social. Producción del conocimiento. Tecnología en la educación.

Recebidas I ${ }^{\text {a }}$ versão em: 12.12.2006

$2^{a}$ versão em: 06.08.2007

Aceita $3^{\mathrm{a}}$ versão em: 22.11 .2007 
